\title{
Health Equity Column: Framing Birth Equity To Protect Black Maternal Health Outcomes
}

Jenné Johns, MPH, Dawn Godbolt, Ph.D.

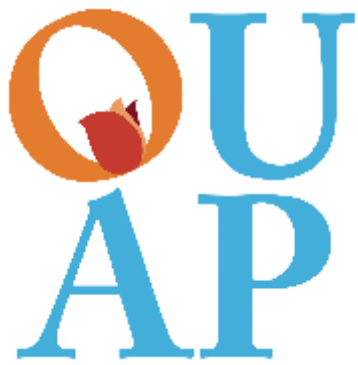

This April marks two important national campaigns that shine a light on inequities in the United States. First is National Minority Health Month, led by the HHS Office of Minority Health. Second is Black Maternal Health Week (April $11^{\text {th }}-17^{\text {th }}$ ) led by the Black Mommas Matter Alliance. This is a global awareness-raising week to address systemic and systematic inequities within the Black Maternal Health crisis while leading advocacy and community engagement opportunities to advance improvements to protect and keep Black mothers and infants alive. These movements require the perinatal and neonatal healthcare community to address the most pressing challenges facing communities of color at the most vulnerable yet deserving time of life- childbearing, childbirthing, and infant rearing. Yet, this opportunity is unequal and unjust for many women in this country due to factors surrounding policy, systems, and institutional bias within healthcare. In this interview, I am honored to share highlights of my interview with a leading policy, advocacy, and community engagement organization, the National Birth Equity Collaborative, led by my colleague and industry mentor, Dr. Joia Crear Perry. She has a lifelong passion and commitment to improving birth outcomes for Black mothers and infants. I'm equally honored to introduce the readers of Neonatology Today to NBEC's Policy Director, Dr. Dawn Godbolt, who is paving the way to ensure the voices and stories of Black mothers and infants are reflected in the necessary and imperative policy and legislative changes required to protect all Black birthing families. Including the equity needs of Black families in the NICU. Through our interview, as you learn about the equity-focused maternal health initiatives led by Dr. Perry, Dr. Godbolt, and the amazing women at NBEC, I encourage you to leverage these resources within your respective institutions and to support the closing of racial and ethnic disparities in perinatal and neonatal health outcomes based on the birth equity framework.

\section{"I'm equally honored to introduce the} readers of Neonatology Today to NBEC's Policy Director, Dr. Dawn Godbolt, who is paving the way to ensure the voices and stories of Black mothers and infants are reflected in the necessary and imperative policy and legislative changes required to protect all Black birthing families."

What is the National Birth Equity Collaborative?
The National Birth Equity Collaborative (NBEC) was established in 2015 by Dr. Joia Crear Perry, MD, FACOG, and is a Black women-led organization that creates solutions that optimize Black maternal and infant health through training, policy advocacy, research, and community-centered collaboration. NBEC is a space where the sexual and reproductive health and wellbeing of Black women is centered in the fight to expand health equity by applying a reproductive justice framework to every aspect of our work. We believe in the value of Black lives, and as such, we work to build solutions to the maternal health crisis that shifts the narrative of blame to one that acknowledges systemic racism as the root cause of maternal health disparities.

\section{What is "Birth Equity," and why was this definition created?}

The term birth equity was coined by NBEC founder and President Dr. Joia Crear-Perry. Birth equity is the assurance of the conditions of optimal births for all people with a willingness to address racial and social inequities in a sustained effort. Birth equity is critical to understanding the various ways systemic oppression like racism, classism, and gender oppression can all impact birth outcomes. A birth equity framework works to create a structure where all people can birth safely. Birth equity is rooted in the reproductive justice framework: the human right to maintain personal bodily autonomy, have children, not have children, and parent the children we have in safe and sustainable communities.

\section{"A birth equity framework works to create a structure where all people can birth safely. Birth equity is rooted in the reproductive justice framework: the human right to maintain personal bodily autonomy, have children, not have children, and parent the children we have in safe and sustainable communities."}

\section{Who are the members of NBEC, and what geographies do you serve?}

NBEC is composed of Black and Brown maternal health experts who serve as thought leaders in the maternal health space. We work to build community through sisterhood across the country

\section{Readers can also follow}

NEONATOLOGY

via our Twitter Feed

@NEO 
and internationally with our work.

- NBEC's Research and Strategy team provides the data and analysis needed to advance birth equity.

- The Training, Evaluation, and Practice team provides technical assistance to programs and systems interested in unpacking the manifestations of racism within their organizations.

- The Policy Shop manages and promotes NBEC's Federal, State, and Local policy and advocacy priorities. The Policy Shop uses a reproductive justice lens to make recommendations to elected officials, key stakeholders, and community-based advocacy groups in an effort to advance birth equity through policy, practice, and programs.

- The Global Birth Equity Team is responsible for NBEC's global projects, advocacy, and partnerships, as well as internal community care for staff members. The team helms initiatives centered on learning from Black women globally, unpacking the harms of the family planning framework, and addressing the impact of climate change and environmental racism on sexual and reproductive health.

- The Birth Equity Scholars program is designed to train and mentor Black and brown doctoral students in the field.

- The Administrative and Finance teams keep us going like a well-oiled machine, manages our interns, and leads our community engagement initiatives.

\section{What personal and professional experiences led you to your leadership role with NBEC?}

As a Black woman in the United States, maternal health outcomes are deeply personal to me. From the earliest age, I understood that something was fundamentally wrong with American society. While working on my Ph.D., my study of sexual and reproductive health led me to identify maternal health as my passion. There is something gut-wrenching about the fact that Black mommies and babies die at such an alarmingly high rate in comparison to our white counterparts. When unpacking the data and analyzing the power structures that influence the Black maternal health crisis, I knew I needed to be a part of the solution. My role at the NBEC comes with the knowledge that I am advocating for myself and my sisters across the country and around the world every day.

\footnotetext{
"When unpacking the data and analyzing the power structures that influence the Black maternal health crisis, I knew I needed to be a part of the solution. My role at the NBEC comes with the knowledge that I am advocating for myself and my sisters across the country and around the world everyday."
}

Describe Black Maternal Health Week and the imperative for advancing health outcomes for Black and Brown birthing women.

Black Maternal Health Week was founded and led by the Black Mamas Matter Alliance (BMMA), of which NBEC is a kindred partner and Dr. Joia Crear-Perry is an advisory committee member. It is a week of awareness, activism, and community building seeking to amplify the voices of Black mamas and uplift reproductive justice. This week also provides a national platform for Black-led organizations advancing efforts on maternal health, birth, and reproductive justice and seeks to really amplify community-based solutions. It's also important to note that BMMA terms "Black Mamas" to represent the full diversity of lived experiences, including all birthing people and all people of African descent across the diaspora.

\section{What is NBEC's call to action for Black Maternal Health Week?}

NBEC is participating in a range of activities during Black Maternal Health Week! On Monday, April $12^{\text {th }}$, we are co-hosting an event with Rep. Lauren Underwood (IL-14), Rep. Alma Adams (NC-12), and leaders in the Reproductive Justice space to introduce the Vanguard of maternal health and, later in the day, our State and Local Policy Analyst will be a featured panelist in a Twitter Town Hall designed to connect audiences and experts to gain insight on the current maternal health space. On Tuesday, April $13^{\text {th }}$, we are partnering with the Institute of Women's Studies (IWES) to host a maternal yoga session, and in partnership with the Commonwealth Fund and Tara Health Foundation, Dr. Joia Crear-Perry will be on the panel to address how philanthropy and organizations can shift culture and improve healthcare conditions. Wednesday, April $14^{\text {th }}$, NBEC's Federal Policy Team will be participating in a live fireside chat with Black Maternal Health Policymakers and experts to provide details on the Black Maternal Health Momnibus Act of 2021. On Thursday, April $15^{\text {th }}$, we will be live on Instagram for a candid conversation about Black Women, COVID-19, Fibroids, and Infertility. And on Friday, April $16^{\text {th }}$, we're rounding out the week by hosting a workshop about liberating voice and vagina. We are really looking forward to BMHW 2021 and hope everyone will tune in!

We are also rolling out many products and deliverables related to our work at NBEC, so keep an eye out on our website!

\section{"NBEC's mission and vision are to optimize Black maternal and infant health so that all Black mothers and babies thrive. This means every step along the way from prenatal to postpartum care."}

\section{What does NBEC mean to the field of neonatology at this time?}

NBEC's mission and vision are to optimize Black maternal and infant health so that all Black mothers and babies thrive. This means every step along the way from prenatal to postpartum care. We seek to address systemic factors that contribute to why Black babies may be born premature, but we also work to ensure that the 
quality and standard of care the baby receives in the NICU is high quality, accessible and addresses structural and social determinants impacting the baby's health outcomes.

\section{How can we learn more about NBEC?}

You can visit our website www.birthequity.org or follow us on social media @birthequity!

Disclosure: The authors have no disclosures.

NT

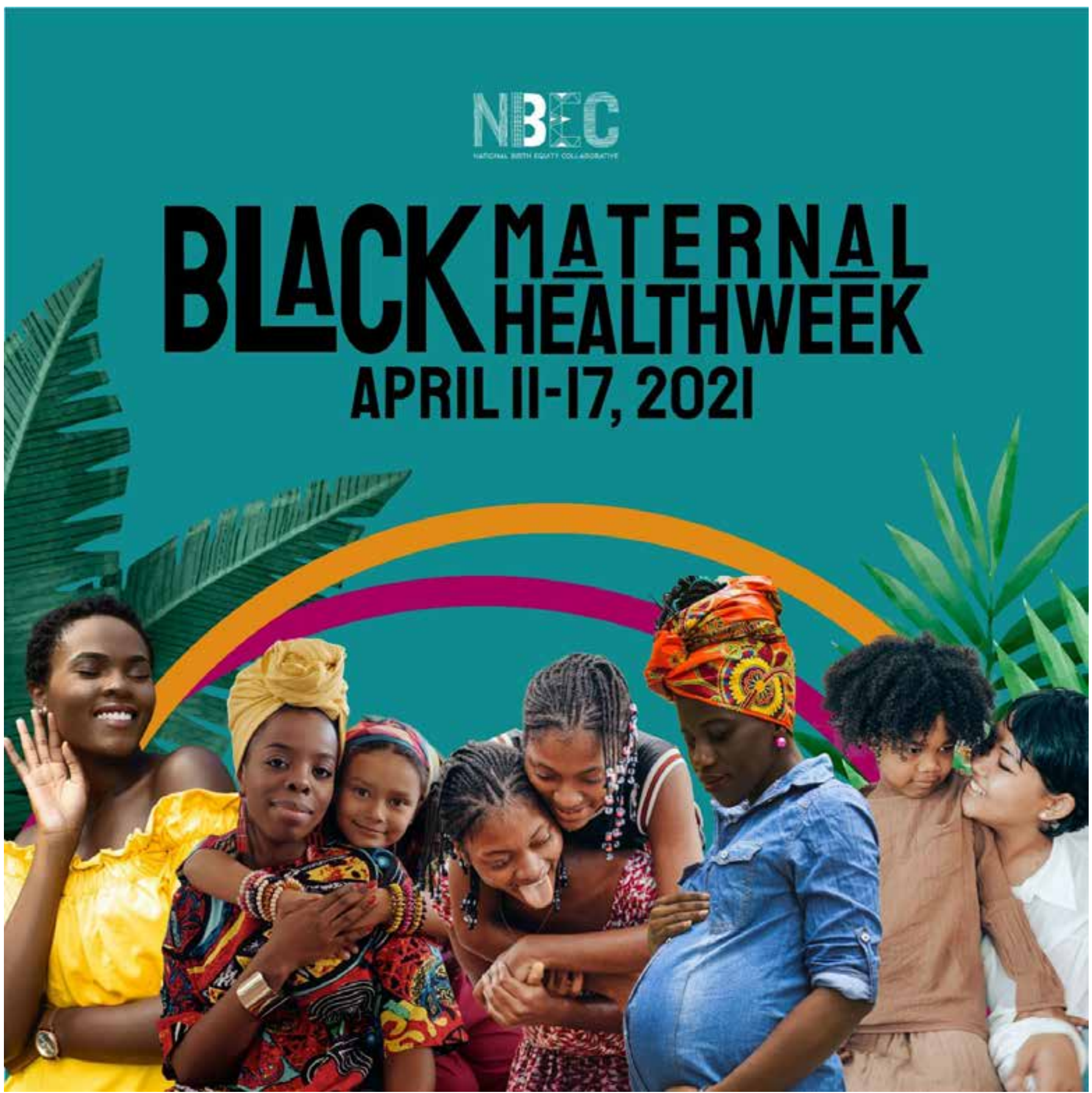




\section{About the Author: Dawn Godbolt, Ph.D.:}

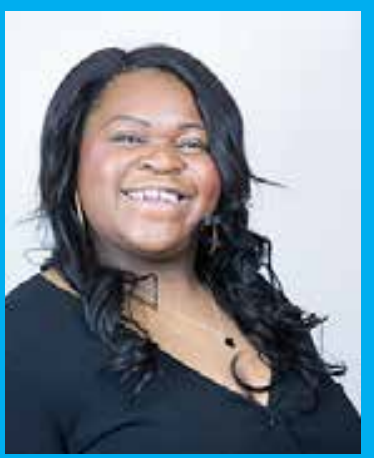

\section{Organization: National Birth Equity Collaborative}

Dawn Godbolt, Ph.D is the Policy Director at the National Birth Equity Collaborative where she works to improve maternal health disparities through federal policy levers. She sits on the National Quality Forum's Maternal Mortality and Morbidity Committee and chairs the Equitable Maternal Health Coalition policy working group. Prior to joining NBEC, Dr. Godbolt was the Senior Manager for Maternal Health initiatives at the National Partnership for Women \& Families. Dr. Godbolt holds a PhD in Sociology from Florida State University, and has completed a fellowship with the OpEd Project to develop her voice as a thought leader.

\section{About the Author: Jenné Johns, MPH:}

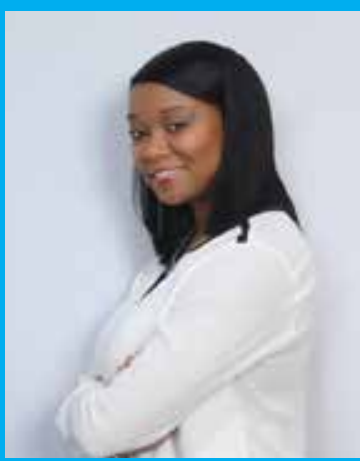

President, Once Upon APreemie www.onceuponapreemie.com

Founder, Once Upon A Preemie Academy www.onceuponapreemieacademy.com

Jenné Johns, MPH is President of Once Upon A Preemie, Founder of Once Upon A Preemie Academy, mother of a micropreemie, author, speaker, advocate, and national senior health equity leader. Once Upon A Preemie is a non-profit organization with a two-part mission: 1.) to donate Once Upon A Preemie books to NICU families in under resourced communities, and 2.) lead virtual health and racial ethnic training programs and solutions to the neonatal and perinatal community through the Once Upon A Preemie Academy. Jenné provides speaking, strategic planning and consultation services for fortune 500 companies focused on preemie parent needs from a cultural lens and reading as a tool for growth, development, and bonding. Jenné is also a national senior health equity thought leader and has led solutionsoriented health equity and quality improvement portfolios for the nations' largest health insurance and managed care companies.

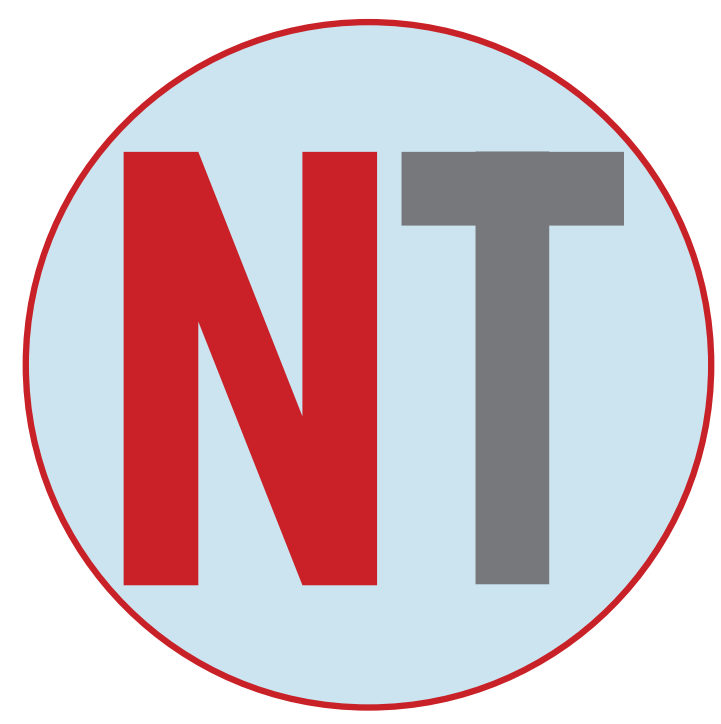

